UNDERGRADUATE RESEARCH IN NATURAL AND CLINICAL SCIENCE AND TECHNOLOGY (URNCST) JOURNAL Read more URNCST Journal articles and submit your own today at: https://www.urncst.com

\title{
A Novel Method for Transplanting Astrocytes to Promote Recovery from Traumatic Brain Injury
}

\author{
Swati Anant, BHSc Student [1]*, Nicholas Lum [1], Tina Wu [1]
}

[1] Department of Health Sciences, McMaster University, Hamilton, Ontario, Canada, L8S 4L8

*Corresponding Author: anants2@mcmaster.ca

\begin{abstract}
Introduction: The recent increase in rates of traumatic brain injury (TBI) has sparked a large

"Research in Earnest"

body of research into its pathophysiology. TBI is characterized as a disruption of brain function following various forms of trauma. Astrocytes, a class of glial cells, play a critical role in TBI recovery by regulating the homeostasis of ions, water and blood flow, and may be subdivided into two categories: A1 reactive astrocytes are produced in response to inflammation and have neurotoxic effects, while A2 astrocytes have been shown to upregulate neurotrophic factors that promote the survival and growth of neurons. This research protocol will outline a novel method for transplantation of A1 and A2 astrocytes in murine models of TBI to explore its potential as a therapeutic intervention.

Methods: The procedure for astrocyte transplantation will involve inducing TBI within a cohort of mice, administering A1 and A2 astrocytes, and testing the behavioral and biological outcomes. These outcomes will be measured via the Morris Water Maze and staining methodologies that assess the structural integrity of the gray and white brain matter. The control group will be a cohort of mice receiving a sham operation.

Results: We anticipate that the mice receiving A2 astrocyte transplants will perform better on the Morris Water Maze tests compared to those who received A1 astrocyte transplants. Additionally, these mice will have higher amounts of both gray and white matter in comparison to the A1 astrocytes transplant group. Sham mice are anticipated to have similar results to the A1 astrocyte transplant group, while mice that receive a combination of A1 and A2 astrocytes are expected to show similar results to the A2 astrocyte transplant group. Finally, transplantations on mice without TBI are expected to have no effect.

Discussion: Results from the Morris Water Maze (MWM) will provide a functional assessment of the impact of astrocyte transplantation on TBI, and staining will provide a structural assessment on overall neurological health of the various cohorts of mice in this study.

Conclusion: This study will allow for a greater understanding of how astrocyte transplantation may benefit individuals who have suffered from TBI.
\end{abstract}

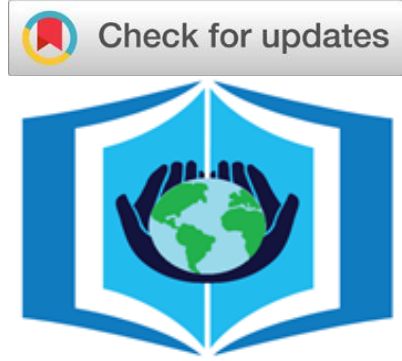

URNCST Journal

Keywords: astrocyte; microglia; reactive astrogliosis; A1; A2; glial transplant; murine model; traumatic brain injury; TBI; concussion

\section{Introduction}

Traumatic brain injury (TBI) is caused by a mechanical force inflicted on the brain, such as a violent blow, resulting in neural tissue damage [1]. It commonly affects individuals under the age of 45 , and results in long-term cognitive deficits and an increased risk of neurodegenerative disorders [2]. At the behavioral level, TBI can result in working memory deficits. TBI clinically presents in varying levels of severity depending on the extent of damage. This type of injury is often accompanied with symptoms such as headaches, nausea, fatigue and sensory problems $[1,3]$.

In determining methods for TBI patients to cope with this type of injury, it is crucial to understand the pathophysiology of brain injuries as a whole. Following any form of brain trauma, there are a series of events that occur. Immediately after the injury, the neural blood supply is interrupted, and many cells die due to an excessive release of glutamate, which can lead to cognitive and motor deficits [4]. The tissues then become swollen and inflamed, and there is a decrease in metabolic activity. Survival following the brain injury is promoted by a number of growth-related mechanisms. Research in neuroplasticity suggests that axonal sprouting in the perilesional cortex (i.e., the area surrounding the injury) can promote spontaneous recovery $[5,6]$.

There are two main phases in TBI pathophysiology: the primary phase and the secondary phase. The primary phase describes the damage that occurs upon onset of the injury, including axonal damage and intracranial hemorrhage. On the other hand, secondary damage is related to damage that only appears a few days following the injury, such as ischemia and swelling [1]. From a neurochemical standpoint, 
UNDERGRADUATE RESEARCH IN NATURAL AND CLINICAL SCIENCE AND TECHNOLOGY (URNCST) JOURNAL Read more URNCST Journal articles and submit your own today at: https://www.urncst.com

TBI has been linked to alterations in intracellular calcium levels. In particular, the neural tissue damage creates an overstimulation of glutamate receptors, which results in an influx of calcium [1]. TBI may also cause altered axolemma permeability, which could lead to the same result of increased intra-axonal calcium through an alternative pathway - the presence of microscopic holes in the axonal membrane $[1,4]$. These elevated intracellular $\mathrm{Ca}^{2+}$ levels contribute to prolonged alterations in neuroplasticity, thus resulting in the long-term effects of TBI. Another impact of increased $\mathrm{Ca}^{2+}$ is the increased mitochondrial uptake of this ion, which induces oxidative stress thus impairing normal function of the mitochondria [4].

TBI recovery is a fascinating, but complex area of research due to the ambiguity in defining the term 'recovery' itself. Despite the astronomical prevalence of TBI and the fact that it is a leading cause of fatality, there are limited treatment strategies. We previously described the alterations in the perilesional cortex that occur following brain injury. However, there are a number of homeostatic cellular mechanisms that have a dichotomous protective and toxic role in TBI recovery. The focus of this paper is on the protective effects of astrocytes, and the ways in which these effects can be further harnessed through transplantation.

Astrocytes are a critical component of brain physiology and pathophysiology, playing a key role in recovery from TBI. In healthy brain tissue, astrocytes maintain the homeostasis of ions, water, and blood flow [7-8]. They are able to sense changes in neuronal activity and composition of extracellular spaces. Astrocytes are heterogeneous in morphology, with a wide variety of receptors and ion channels [7]. It is unclear as to how astrocytes are able to transduce physical strain into alterations in cellular activity. However, it is proposed that membrane deformation may activate mechanosensitive ion channels in astrocytes along with the mitogen-activated protein kinase signaling pathway [8].

Following neural tissue damage, astrocytes undergo reactive astrogliosis which involves functional, morphological, and molecular changes. In general, astrocyte response involves the production of cytokines, chemokines and danger-associated molecular patterns (DAMPs), along with stress-associated alarmins. DAMP stimulation results in nuclear-factor- $\kappa \mathrm{B}(\mathrm{NF} \kappa \mathrm{B})$ signaling, the production of proinflammatory cytokines like tumor necrosis factor $\alpha(\mathrm{TNF} \alpha)$ and $\alpha$-chemokines [8]. Following TBIs, common reactive astrocytes are the A1 and A2 subtypes, which can be produced in response to neuroinflammation induced by lipopolysaccharide injection and middle cerebral artery occlusion respectively. A1 reactive astrocytes are the consequence of inflammatory mediators released from microglial cells. This subtype is considered neurotoxic and neuroinflammatory. A1 astrocytes have been shown to decrease the excitatory function of synapses. Meanwhile, A2 astrocytes have been shown to upregulate neurotrophic factors that promote survival and growth of neurons $[7,9]$.
To obtain a stronger understanding of the protective and toxic roles of $\mathrm{A} 1$ and $\mathrm{A} 2$ astrocytes in TBI patients, we are proposing the transplantation of astrocytes through utilizing an induced-TBI murine model. It is possible that these astrocyte subtypes interact with one another, and studies have indicated the possibility of class-switching among subtypes [10]. For this reason, it is crucial to study the effects of transplantation of both subtypes and determine their physiological and behavioral effect on cognitive function.

\section{Methods}

The method we are proposing for astrocyte transplantation involves first inducing TBI within a cohort of mice, and then obtaining $\mathrm{A} 1$ and $\mathrm{A} 2$ astrocytes from alternate cohorts of mice in order to transplant these cells into the TBI-inflicted mice, as well as a control group receiving a sham operation. Finally, we propose to test the cellular and cognitive outcomes of this transplant using the Morris Water Maze and staining to determine the extent of healing.

Procedure 1: Inducing Traumatic Brain Injury

The previous literature on this topic outlines several different methods for inducing TBI in murine models; however, we are proposing to implement the controlled cortical impact (CCI) model [11-12]. Upon arrival, all mice will be housed under a 12-hour light/dark cycle with access to food and water and given a 5-day period to acclimate. Following the acclimation period, mice will receive either a severe TBI or sham operation. For the procedure, mice will be anesthetized and placed in a stereotaxic frame. Body temperature will be measured via a rectal probe. A craniotomy is performed, exposing a small section of the brain. The electro-magnetic piston will be placed at the surface of the brain and a single discharge will be elicited to produce a severe TBI. Following the injury, the bone flap was immediately replaced, and the scalp is closed with sutures [11].

Thus, there will be two cohorts of mice that are primarily being studied. Cohort A will receive a CCI operation, and cohort B will receive a sham operation. The sham controls will undergo identical procedures as cohort A, excluding the discharge of the piston.

\section{Procedure 2: Extracting Astrocytes}

The methods utilized to extract A1 and A2 astrocytes will encompass induced reactive astrogliosis via brain injury. The mice will be divided into two separate cohorts: one cohort (A1) will be used to extract A1 astrocytes, and the other cohort (A2) will be used to extract A2 astrocytes.

Mice in the A1 cohort will be administered an intraperitoneal lipopolysaccharide (LPS) injection to induce neuroinflammatory A1 astrocytes. The injection will consist of a single dose of $5 \mathrm{mg} / \mathrm{kg}$ of the endotoxin LPS from Escherichia coli O55:B55 (Sigma-Aldrich) dissolved in normal saline solution and diluted into endotoxin-free phosphate-buffered saline (PBS). This intervention elicits a 
UNDERGRADUATE RESEARCH IN NATURAL AND CLINICAL SCIENCE AND TECHNOLOGY (URNCST) JOURNAL Read more URNCST Journal articles and submit your own today at: https://www.urncst.com

microglial response to inflammatory cytokines, leading to the activation of astrocytes [13].

In the A2 cohort, the mice will be subjected to focal ischemic stroke produced by middle cerebral artery occlusion (MCAO) to induce A2 astrocytes. MCAO will be performed for a duration of 1 hour, followed by reperfusion. This will result in the destruction of parts of the cortex, striatum, and hippocampus, with the lesion marked by extensive cell death. The damage elicits a reactive response from the A2 astrocytes in the tissues surrounding the lesion [13].

The astrocytes will be isolated from the cortices of the mice, and the other parts of the brain will be discarded. While the brains are kept in cold PBS, the meninges will be removed under a dissection microscope. Mechanical dissociation of cortices will be performed by passing it through a $22 \mathrm{G}$ sterile needle. The reaction will be stopped, and the cells will be pelleted by centrifugation. The collected cell mixture will be cultured and then passed [13-14].

In order to determine whether the extracted astrocytes are in fact A1 or A2 astrocytes, we would characterize the cells using flow cytometry. In this technique, cells will be labelled using antibodies containing a predetermined set of cell-surface markers [14-15]. Glial fibrillary acidic protein (GFAP) is a cell-surface marker for both subtypes of astrocytes. Further categorization of the subtypes will be determined by the presence or absence of complement component 3 (C3), a marker of A1 astrocytes. S100a10 will be used to uniquely identify A2 astrocytes [16].

\section{Procedure 3: Transplanting Astrocytes}

Reactive astrocytes will be transplanted into both Cohort A and Cohort B (mice that received the TBI procedure and the sham procedure, respectively). These two cohorts will each be subdivided into four sections: an A1 astrocyte transplant group, an A2 astrocyte transplant group, a group where both subtypes are transplanted in equal proportions, and a control group that does not undergo transplantation, as seen in Figure 1.
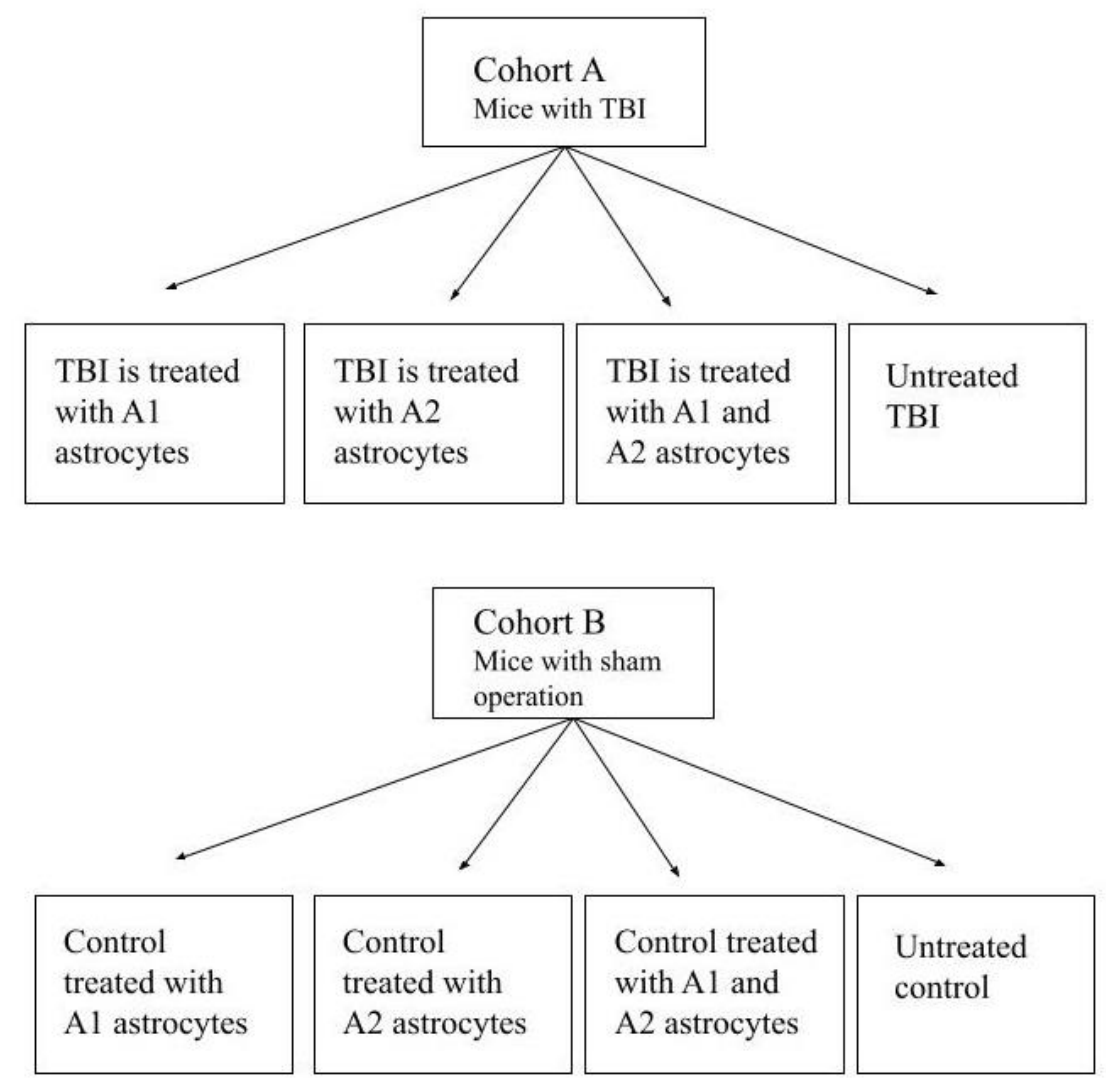

Figure 1. Division of TBI-afflicted and sham murine cohorts into experimental groups. The cohort A mice (i.e., mice that received the CCI operation) will be subdivided into four groups: one that receives A1 astrocytes, another receiving A2 astrocytes, a group that receives both A1 and A2 astrocytes, and a control group that does not undergo transplantation. The cohort B mice (i.e., mice that received the sham operation) will be subdivided into similar categories.

Concentrated reactive astrocyte suspensions will be loaded into a micro syringe. Micro syringes will be positioned in a stereotactic injection apparatus. Mice will be anesthetized, and a craniotomy will be performed. The 
UNDERGRADUATE RESEARCH IN NATURAL AND CLINICAL SCIENCE AND TECHNOLOGY (URNCST) JOURNAL Read more URNCST Journal articles and submit your own today at: https://www.urncst.com

astrocyte injections will be made into the primary somatosensory cortex. After transplantation, the bone flap will be replaced, and incisions closed. Afterwards, the mice will remain on a heating pad before being returned to their cages. This procedure is repeated for both $\mathrm{A} 1$ and $\mathrm{A} 2$ astrocyte transplantation. For the control procedure, the craniotomy will be performed, but no astrocytes are transplanted [17].

\section{Procedure 4: Testing Outcomes}

One month after the astrocyte transplantation, behavioural outcomes will be assessed using the MWM. A $120 \mathrm{~cm}$ diameter circular tank of water will be set up with a submerged escape platform. Distal spatial cues will be placed around the room in the form of posters of large geometric shapes. To reduce non-spatial memory related behaviours, such as thigmotaxis, the mice will enter a cued training trial to learn that the platform is the only method of escape from the maze. Then, for each of 5 consecutive days, the mice will undergo hidden platform training trials. Mice are placed in a different location each trial and must use the visual cues around the room to reach the submerged escape platform to test spatial navigation, rather than relying on a memorized path to reach the goal. Finally, there will be a probe trial where the platform is removed to assess the mice's memory of the platform position. The mice with a greater memory capacity for the learned spatial information will stay longer in the area the platform used to be and may cross the exact location more often [18].

After the water maze tests are completed, the mice will be decapitated, and brain removed. The brain will be perfused with formaldehyde and embedded into paraffin wax. Next, a microtome will thinly slice the brain. The slices will be mounted onto slides and left to dry. Staining will be performed. Gray matter integrity will be assessed with 'cresyl violet' staining, while white matter integrity will be assessed by staining for 'luxol fast blue'. Light microscopy will be used to view the specimens for signs of brain damage and/or repair [19].

\section{Results}

It is expected that there will be differences in outcomes between subsets of mice depending on their exposure and intervention. Treating TBI-inflicted mice with A1 astrocytes is expected to result in adverse neurological outcomes due the cells' neurotoxic nature, resulting in neuronal death across cohorts. This would be demonstrated by poorer results on the water maze test and decreased gray and white brain matter compared to the untreated TBI-inflicted mice. Sham mice that receive the $\mathrm{A} 1$ astrocyte transplant are expected to show similar adverse neurological outcomes. In contrast, the transplantation of both subtypes is expected to produce positive results, similar to what we would expect in the transplantation of $\mathrm{A} 2$ astrocytes. It is possible that the mice may promote the division of A2 astrocytes and perhaps downregulate A1 astrocytes due to their neurotoxic effects.
Similarly, TBI-inflicted mice receiving A2 astrocytes are expected to perform better on the water maze test compared to the untreated population, thus exhibiting an improvement in cognitive ability. They are anticipated to have increased gray and white brain matter, indicating neuronal healing. Meanwhile, A2 astrocyte transplantation is hypothesized to have no effect on mice who did not receive a TBI (i.e., mice who received the sham operation).

We expect this protocol to take approximately 6 months to execute in order to provide for adequate time to adjust methods and repeat trials.

\section{Discussion}

The procedure outlined for transplanting astrocytes will provide insight into both the pathophysiological role of astrocytes and their therapeutic implications. The effectiveness of astrocyte transplantation in TBI recovery is measured with the MWM experiment and neuronal staining. Together, these methods provide both a functional and structural assessment of neurological health.

The MWM was chosen as a method to evaluate the progress of the mice cohorts seeing as this is a welldocumented, valid and broad measure of overall cognitive health. It has been used in previous studies to analyze different types of memory and spatial learning abilities. Since TBI itself has a plethora of clinical presentations and astrocyte transplantations in this form have not been performed in the past, the MWM would be a good way to characterize general neurological improvement. Effects on MWM performance after treatment have been more widely replicated than the effects observed with any other learning task. The MWM has the additional advantage of being relatively easy to set up [18].

To accompany this behavioural assessment, staining provides a stronger visual representation of the impact of astrocyte transplantation and will be used as a general assessment of brain recovery.

If this preliminary study yields successful results - that is, the mice exhibit an improvement in the MWM and they have increased levels of gray and white matter, further studies can be performed to examine the specifics of the mechanism. For example, it is unclear as to whether the astrocytes subtypes will differentiate again after transplantation (i.e., A1 transforming into A2 after exposure to the TBI). Additionally, the impact of these astrocyte subtypes on glial scar formation is largely unknown. Thus, future studies should attempt to discern the specific outcomes of astrocyte transplantation, along with its possible positive or negative implication in glial scar formation.

\section{Conclusions}

The pathophysiology of TBI is complex, and therefore it is challenging to develop appropriate treatment options. Previous literature describes the involvement of astrocytes in neural repair after TBI, however, it details a difference between the effects of $\mathrm{A} 1$ and $\mathrm{A} 2$ reactive astrocyte 
UNDERGRADUATE RESEARCH IN NATURAL AND CLINICAL SCIENCE AND TECHNOLOGY (URNCST) JOURNAL Read more URNCST Journal articles and submit your own today at: https://www.urncst.com

subtypes. This study will allow us to determine whether these astrocytes, specifically those of the A2 subtype, can promote neural regeneration. However, further research will still be required in order to determine whether these subtypes are capable of class-switching and differentiating into alternate varieties of astrocytes following transplantation. Additionally, an anticipated challenge in this research will be applying these procedures to human subjects to determine the efficacy of this treatment. Overall, understanding the potential benefits to the transplantation of astrocytes in TBIinflicted individuals will open doors to new areas of research.

\section{List of Abbreviations Used}

C3: complement component 3

CCI: controlled cortical impact

DAMP: danger-associated molecular pattern

GFAP: glial fibrillary acidic protein

GLAST-1: glutamate aspartate transporter 1

LPS: lipopolysaccharide

MCAO: middle cerebral artery occlusion

$\mathrm{NF} \kappa \mathrm{B}$ : nuclear-factor- $\kappa \mathrm{B}$

PBS: phosphate-buffered saline

TBI: traumatic brain injury

TNF $\alpha$ : tumor necrosis factor $\alpha$

\section{Conflicts of Interest}

The authors declare that they have no conflict of interests.

\section{Ethics Approval and/or Participant Consent}

This research protocol does not require human participants. The use of murine models will require ethics approval, should this protocol be performed in the future.

\section{Authors' Contributions}

SA: made contributions to the design of the study, assisted in writing the introduction and conclusion, and revised the methods section.

NL: contributed to study design and planning, assisted in writing the introduction and methods sections and revised the entire document.

TW: made contributions to the design of the study, assisted in writing the introduction and methods sections of the paper and revised the entire document.

\section{Acknowledgements}

We would like to acknowledge Prashanth Velayudhan, our mentor from the URNCST, who guided us in developing a clear method for our research protocol and provided feedback for our final draft of this paper.

\section{Funding}

This study was not funded.

\section{References}

[1] Ng SY, Lee AY. Traumatic brain injuries: Pathophysiology and potential therapeutic targets. Frontiers in Cellular Neuroscience. 2019;13. https://doi.org/10.3389/fncel.2019.00528

[2] Marquez de la Plata CD, Hart T, Hammond FM, Frol AB, Hudak A, Harper CR, et al. Impact of age on longterm recovery from traumatic brain injury. Archives of Physical Medicine and Rehabilitation. 2008;89(5):896903. https://doi.org/10.1016/j.apmr.2007.12.030

[3] Dixon KJ. Pathophysiology of traumatic brain injury. Physical Medicine and Rehabilitation Clinics of North America. 2017;28(2):215-25. https://doi.org/10.1016/ j.pmr.2016.12.001

[4] Guerriero RM, Giza CC, Rotenberg A. Glutamate and GABA imbalance following traumatic brain injury. Current Neurology and Neuroscience Reports. 2015;15(5). https://doi.org/10.1007/s11910-015-0545-1

[5] Hylin MJ, Kerr AL, Holden R. Understanding the mechanisms of recovery and/or compensation following injury. Neural Plasticity. 2017;2017:1-12. https://doi.org/10.1155/2017/7125057

[6] Laskowitz D, Grant G. Translational research in traumatic brain injury. CRC Press; 2016. https://doi.org/10.1201/b18959

[7] Belanger M, Magistretti P. The role of astroglia in neuroprotection. Neurotoxicity and Neuroprotection. 2009;11(3):281-95. https://doi.org/10.31887/dcns.2009 $.11 .3 / \mathrm{mbelanger}$

[8] Sofroniew MV. Astrocyte reactivity: Subtypes, states, and functions in CNS innate immunity. Trends in Immunology. 2020;41(9):758-70. https://doi.org/ 10.1016/j.it.2020.07.004

[9] Boghdadi AG, Teo L, Bourne JA. The neuroprotective role of reactive astrocytes after central nervous system injury. Journal of Neurotrauma. 2020;37(5):681-91. https://doi.org/10.1089/neu.2019.6938

[10] Liu L-rong, Liu J-chen, Bao J-shuang, Bai Q-qin, Wang G-qing. Interaction of microglia and astrocytes in the neurovascular unit. Frontiers in Immunology. 2020;11. https://doi.org/10.3389/fimmu.2020.01024

[11] Cannella LA, Andrews AM, Tran F, Razmpour R, McGary H, Collie C, et al. Experimental traumatic brain injury during adolescence enhances cocaine rewarding efficacy and dysregulates dopamine and neuroimmune systems in brain reward substrates. Journal of Neurotrauma. 2020;37(1):27-42. https://doi.org/10.1089/neu.2019.6472

[12] Dean DD, Frank JA, Turtzo LC. Controlled cortical impact in the rat. Current Protocols in Neuroscience. 2017;81(1). https://doi.org/10.1002/cpns.37

[13]Zamanian JL, Xu L, Foo LC, Nouri N, Zhou L, Giffard $\mathrm{RG}$, et al. Genomic analysis of reactive astrogliosis. Journal of Neuroscience. 2012;32(18):6391-410. https://doi.org/10.1523/jneurosci.6221-11.2012 
UNDERGRADUATE RESEARCH IN NATURAL AND CLINICAL SCIENCE AND TECHNOLOGY (URNCST) JOURNAL Read more URNCST Journal articles and submit your own today at: https://www.urncst.com

[14] Bernard-Patrzynski F, Lécuyer M-A, Puscas I, Boukhatem I, Charabati M, Bourbonnière L, et al. Isolation of endothelial cells, pericytes and astrocytes from mouse brain. PLOS ONE. 2019;14(12). https://doi.org/10.1371/journal.pone.0226302

[15] Liddelow SA, Barres BA. Reactive astrocytes: Production, function, and therapeutic potential. Immunity. 2017;46(6):957-67. https://doi.org/10.1016/ j.immuni.2017.06.006

[16]Zou L-H, Shi Y-J, He H, Jiang S-M, Huo F-F, Wang $\mathrm{X}-\mathrm{M}$, et al. Effects of FGF2/FGFR1 pathway on expression of A1 astrocytes after infrasound exposure. Frontiers in Neuroscience. 2019;13. https://doi.org/ $\underline{10.3389 / \text { fnins.2019.00429 }}$
[17]Zhang K, Chen C, Yang Z, He W, Liao X, Ma Q, et al. Sensory response of transplanted astrocytes in adult mammalian cortex in vivo. Cerebral Cortex. 2016;26 (9):3690-704. https://doi.org/10.1093/cercor/bhw213

[18] Tucker LB, Velosky AG, McCabe JT. Applications of the Morris water maze in translational traumatic brain injury research. Neuroscience \& Biobehavioral Reviews. 2018;88:187-200. https://doi.org/10.1016/ j.neubiorev.2018.03.010

[19]Zhang J, Xiong H. Brain tissue preparation, sectioning, and staining. Springer Protocols Handbooks. 2013;330. https://doi.org/10.1007/978-1-4614-8794-4_1

\section{Article Information}

Managing Editor: Jeremy Y. Ng

Peer Reviewers: Prashanth Velayudhan, Foram Vyas

Article Dates: Received Apr 19 21; Accepted Jul 01 21; Published Aug 0521

\section{Citation}

Please cite this article as follows:

Anant S, Lum N, Wu T. A novel method for transplanting astrocytes to promote recovery from traumatic brain injury.

URNCST Journal. 2021 Aug 05: 5(8). https://urncst.com/index.php/urncst/article/view/276

DOI Link: https://doi.org/10.26685/urncst.276

\section{Copyright}

(c) Swati Anant, Nicholas Lum, Tina Wu. (2021). Published first in the Undergraduate Research in Natural and Clinical Science and Technology (URNCST) Journal. This is an open access article distributed under the terms of the Creative Commons Attribution License (https://creativecommons.org/licenses/by/4.0/), which permits unrestricted use, distribution, and reproduction in any medium, provided the original work, first published in the Undergraduate Research in Natural and Clinical Science and Technology (URNCST) Journal, is properly cited. The complete bibliographic information, a link to the original publication on http://www.urncst.com, as well as this copyright and license information must be included.

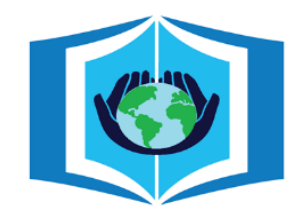

\section{URNCST Journal \\ "Research in Earnest"}

\section{Funded by the Government of Canada}

\section{Canadà̀}

Do you research in earnest? Submit your next undergraduate research article to the URNCST Journal!

| Open Access | Peer-Reviewed | Rapid Turnaround Time | International |

| Broad and Multidisciplinary | Indexed | Innovative | Social Media Promoted |

Pre-submission inquiries? Send us an email at info@ urncst.com | Facebook, Twitter and LinkedIn: @URNCST

Submit YOUR manuscript today at https://www.urnest.com! 